DOI: $10.12731 / 2306-1561-2013-4-9$

\title{
AUTOMATED WAREHOUSE MANAGEMENT CONCRETE PRODUCTS
}

\section{Jha Prabhakar, Ostroukh A.V.}

\section{Abstract}

The possibilities of the method of radio-frequency automatic identification of objects and their application in automated warehouse management systems of concrete products.

Keywords: warehouse management, automated control system, concrete products, RFID objects, registration of products.

\section{УДК 681.3}

\section{АВТОМАТИЗИРОВАННАЯ СИСТЕМА УПРАВЛЕНИЯ СКЛАДОМ ЖЕЛЕЗОБЕТОННЫХ ИЗДЕЛИЙ}

\section{Джха Прабхакар, Остроух А.В.}

\section{Аннотация}

В статье рассмотрены возможности метода автоматической радиочастотной идентификации объектов и их применения в автоматизированных системах управления складом железобетонных изделий.

Ключевые слова: управление складом, автоматизированная система управления, железобетонные изделия, радиочастотная идентификация объектов, учет продукции.

RFID - метод автоматической радиочастотной идентификации объектов, в котором посредством радиосигналов считываются или записываются данные, хранящиеся в так называемых RFID-метках, закрепляемых на учитываемых объектах. Метка может содержать данные о типе объекта, стоимости, весе, температуре, данные логистики, а также любой информации об объекте, с возможностью ее удобного считывания. RFID - современная технология идентификации, предоставляющая существенно больше возможностей по сравнению с традиционными системами маркировки.

Одна из наиболее перспективных областей для внедрения RFID это логистика на крупных промышленных предприятиях. Основные функции RFID-системы на предприятиях промышленности:

- учет поступающей на склад продукции;

- учет уходящей со склада продукции;

- учет складских остатков; 
- интеграция в существующую систему;

- быстрый поиск на складе;

- возможность проведения быстрой инвентаризации;

- контроль заготовок и деталей на всех этапах производства.

Так, как RFID-системы являются довольно новым направлением в данной сфере, поясним, как работает такая система на примере учета продукции завода железобетонных изделий. Общая структура системы управления изображена на следующей схеме (рисунок 1) [1 - 10].

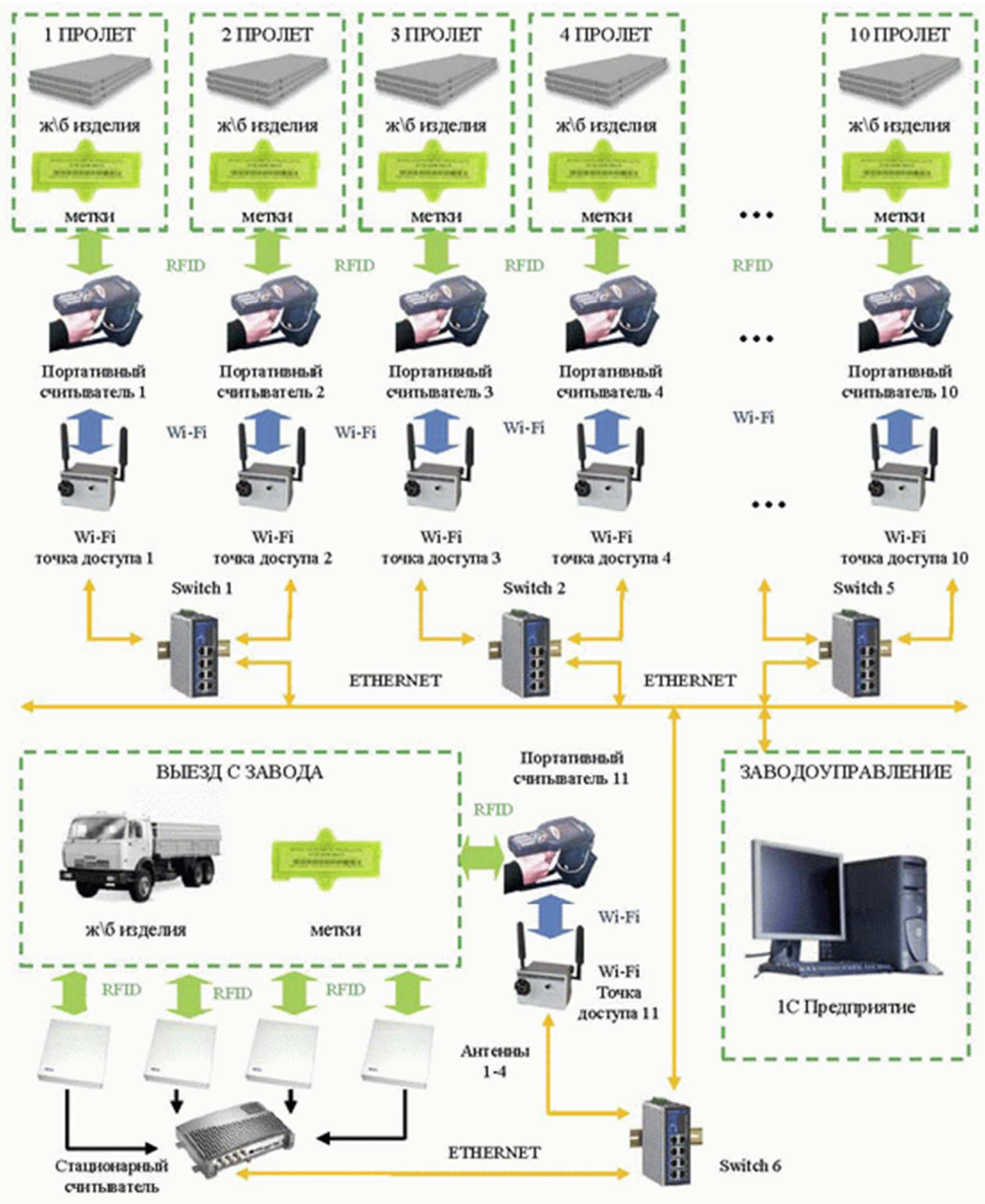

Рисунок 1 - Общая структура автоматизированной системы управления складом 
Автоматизированная система управления складом предусматривает применение различных устройств и технических средств, представленных на рисунке 2.

Даная система предусматривает закладку в каждое изделие (на этапе формовки) метки, разработанной специально для маркировки бетонных изделий. Размеры метки малы. Эти метки пассивные, то есть излучают радиосигнал только когда попадают в зону излучения устройства чтения или записи. Уже после закладки меток возможна запись любой необходимой информации - о предприятии, железобетонном изделии, номере бригады, времени выпуска изделия и т.д. Чипы меток гарантируют уникальность содержащихся в них идентификаторов (ID), что является гарантией неподделываемости каждой метки. Метки надежно функционируют при температуре от - 40 до $+80{ }^{0} \mathrm{C}$. Они долговечны. Работают в любых погодных условиях.

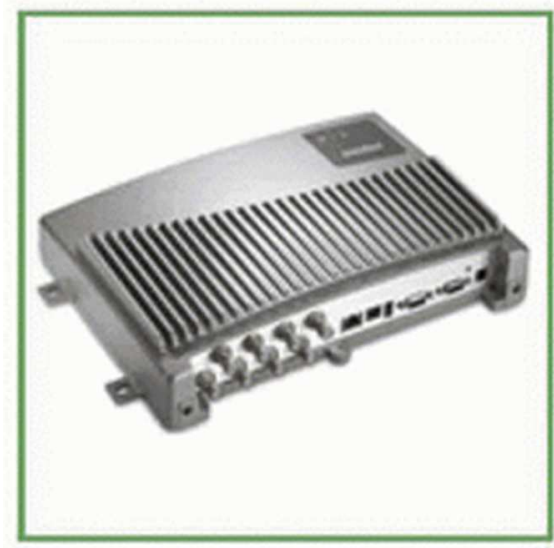

Стационарный считыватель

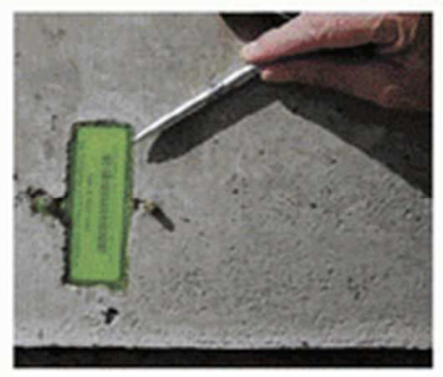

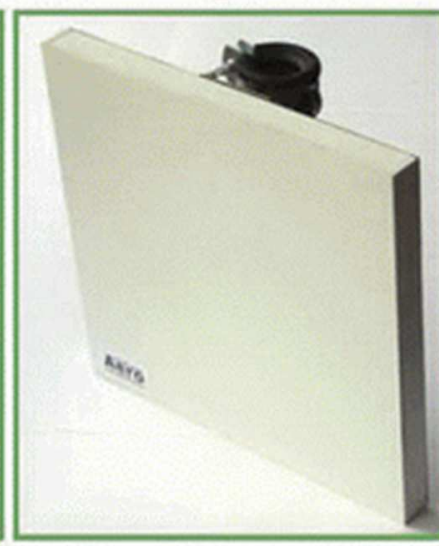

RFIDантенна

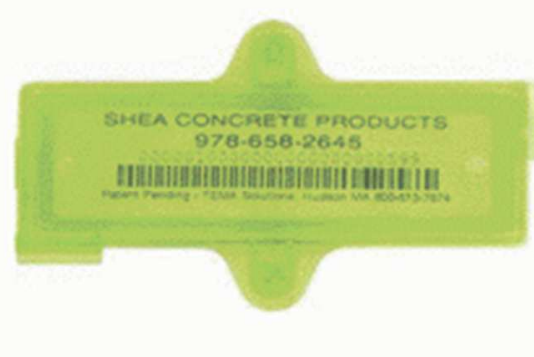

Метка

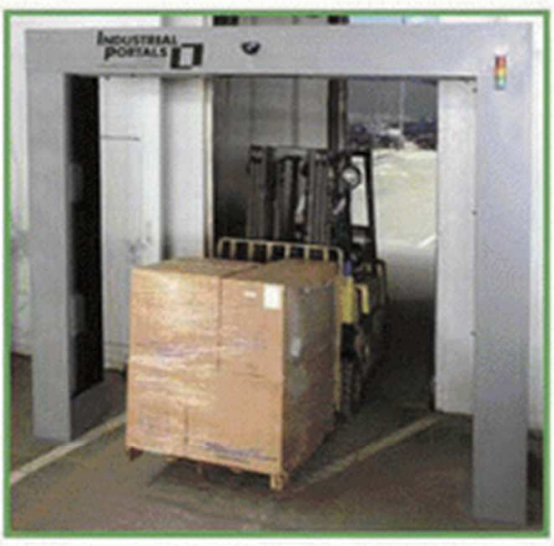

RFID eopoma

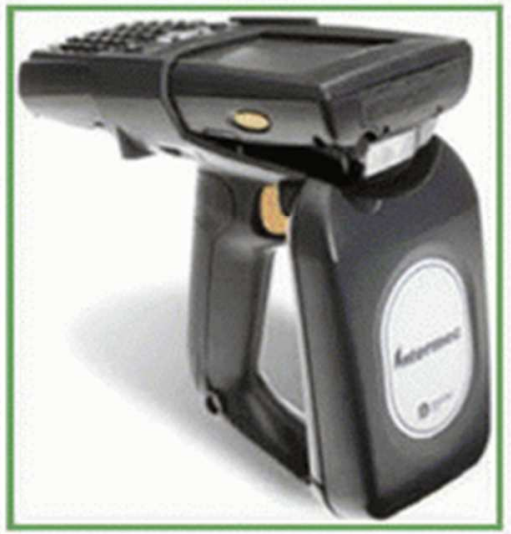

Переносной считыватель

\section{Рисунок 2 - Устройства и технические средства автоматизированной системы} управления складом железобетонных изделий

C помощью портативного ручного устройства записи/чтения (в конце цикла производства) считывается идентификатор метки каждого изделия. Далее оператор в меню портативного устройства выбирает тип данного железобетонного изделия и присваивает данному идентификатору выбранный тип. Можно также вначале считать 
все идентификаторы меток требуемых изделий, а затем присвоить выбранный тип сразу всем изделиям или группе изделий.

Портативное устройство записи/чтения по сети Wi-Fi далее передает эти данные в $1 \mathrm{C}$ Предприятие. Данными устройствами обеспечиваются операторы в каждом из 10 пролетов.

Далее изделия с метками складируются на территории предприятия. Обычно изделия хранят на открытом воздухе вертикально, плотно прижатыми друг к другу. Для того, чтобы найти необходимые изделия, не требуется заниматься их перемещением. Достаточно пронести рядом с ними сканер. Аналогичным образом можно производить инвентаризацию склада.

На выезде с территории устанавливается стационарное устройство чтения, сопряженное с четырьмя антеннами. Стационарное устройство автоматически дистанционно сканирует все метки изделий, находящихся в кузове грузового автомобиля. Полученная информация, по сети, поступает в 1С Предприятие, где автоматически обрабатываются. В случае обесточивания стационарного считывателя на выезде с предприятия, идентификаторы меток изделий (покидающих территорию предприятия) записываются вручную в память резервного портативного устройства, которое, через сеть Wi-Fi передает эти данные в 1C.

На примере рассмотренной системы показана одна из возможных схем реализации. Конечно, для каждого конкретного предприятия система разрабатывается под конкретные задачи и требования заказчика. Обычно совместно вырабатывается такой проект, который наиболее полно реализует идеологию RFID на Вашем предприятии и сделает учет и контроль на производстве, а также складах удобным и прозрачным.

\section{Список информационных источников}

[1] Джха Прабхакар, Джха Пунам. Создание автоматизированной системы контроля и управления качеством в производстве сборного железобетона // Автоматизация и управление в технических системах. - 2012. - № 1; URL: auts.esrae.ru/1-8 (дата обращения: 29.10.2013).

[2] Кузнецов И.А. Особенности реализации автоматизированной информационноаналитической системы центра планирования перевозок строительных грузов / И.А. Кузнецов, А.В. Остроух // Вестник МАДИ(ГТУ). - 2008. - Вып. 1(12). - С. $92-$ 96.

[3] Куфтинова Н.Г. Процессно-ориентированный подход к автоматизации планирования и управления транспортировкой продукции предприятий промышленности / А.В. Остроух, Н.Г. Куфтинова // Вестник МАДИ - 2010. - Вып. 4(23). - C. 62-66.

[4] Куфтинова Н.Г. Разработка информационно- логической модели транспортной сети мегаполиса/ А.В. Остроух, Н.Г. Куфтинова // Бюллетень транспортной информации. - М.: Национальная ассоциация транспортников, 2013. - №1 (211). C. 23-26 
[5] Николаев А.Б. Информационные технологии в менеджменте и транспортной логистике: учебное пособие / А.Б. Николаев, А.В. Остроух. - Saint-Louis, MO, USA: Publishing House Science and Innovation Center, 2013. - 254 c. - ISBN 978-0615-67110-9.

[6] Остроух А.В. Автоматизация распределения транспортных средств и техники по объектам строительства с учетом организационных и технических факторов / A.B. Остроух, Н.Е.Суркова // Приборы и системы. Управление, контроль, диагностика. - М.: «Научтехлитиздат», 2004. - №12. - С. 6-9.

[7] Остроух А.В. Автоматизация и моделирование работы предприятий по строительству промышленных объектов: дис. ... д-ра техн. наук: 05.13.06: защищена 07.04.09: утв. 19.06.09. - М., 2009. - 357 с.

[8] Остроух А.В. Автоматизация и моделирование работы предприятий по строительству промышленных объектов: автореф. дис. ... д-ра техн. наук: 05.13.06. - М., 2009. - 43 c.

[9] Остроух, А.В. Информационные технологии в научной и производственной деятельности / [ред. А.В. Остроух] - М: ООО "Техполиграфцентр", 2011. - 240 с. ISBN 978-5-94385-056-1.

[10] Ostroukh A.V., Kuftinova N.G. Automation of Planning and Management of the Transportation of Production for Food Processing Industry Enterprises. Automatic Control and Computer Sciences. 2012. Vol. 46. No. 1. pp. $41-48$. 